\title{
Venovenous extracorporeal membrane oxygenation in obese patients
}

Jeffrey Javidfar, MD, ${ }^{\text {a }}$ Akram M. Zaaqoq, MD, MPH, ${ }^{\mathrm{b}}$ Michael H. Yamashita, MD,${ }^{\mathrm{c}}$ Greg Eschun, MD, ${ }^{\mathrm{d}}$ Jeffrey P. Jacobs, MD, ${ }^{\mathrm{e}}$ Silver Heinsar, MD, ${ }^{\mathrm{f}}$ Jeremiah W. Hayanga, MD, MPH, ${ }^{\mathrm{g}}$ Giles J. Peek, MD, ${ }^{\mathrm{e}}$ and Rakesh C. Arora, $\mathrm{MD}, \mathrm{PhD}^{\mathrm{c}}$

Feature Editor's Note-The use of venovenous ( $V V)$ extracorporeal membrane oxygenation (ECMO) has experienced broader adoption over the preceding decade for the management of respiratory failure. As experience with VV-ECMO has grown, VV-ECMO has been applied to more patients afflicted with a greater burden of comorbidities, which has been particularly evident during the global COVID-19 pandemic. One of the more common comorbidities is that of obesity. The use of VV ECMO in obese patients poses significant challenges and requires adoption of different techniques to achieve adequate respiratory support and successful outcomes. In this Invited Expert Technique article, Javidfar and colleagues review respiratory management and VV-ECMO techniques for application in obese patients. The authors discuss optimal respiratory management practices including use of esophageal pressure monitoring to assess lung pressures and special considerations in use of prone positioning. Optimal cannulation techniques are reviewed as well as techniques to obtain optimal ECMO flow, gas exchange and oxygenation, and facilitate airway management and physical therapy. Importantly, the authors review thresholds and situations in which conversion to veno-arterial ECMO might be necessary. Javidar and colleagues should be congratulated on a timely, insightful, and comprehensive review on the topic

\footnotetext{
From the ${ }^{\text {aDivision }}$ of Cardiothoracic Surgery, Department of Surgery, Emory School

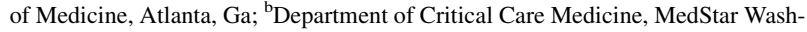
ington Hospital Center, Georgetown University, Washington, DC; ${ }^{\mathrm{c}}$ Section of Cardiac Surgery, Department of Surgery, and ${ }^{\mathrm{d}}$ Critical Care Medicine, University of Manitoba, Winnipeg, Manitoba, Canada; ${ }^{\mathrm{e}}$ Department of Surgery, Congenital Heart Center, University of Florida, Gainesville, Fla; ${ }^{\mathrm{f}}$ Critical Care Research Group, The Prince Charles Hospital and University of Queensland, Brisbane, Queensland, Australia; and ${ }^{\mathrm{g}}$ Department of Cardiovascular and Thoracic Surgery, West Virginia University, Morgantown, WVa.

Internal funds were used to support this work.

G.P. and R.A. contributed as co-senior authors.

Received for publication April 30, 2021; accepted for publication Aug 18, 2021; available ahead of print Oct 28, 2021.

Address for reprints: Jeffrey Javidfar, MD, Division of Cardiothoracic Surgery, Department of Surgery, Emory School of Medicine, 1365 Clifton Rd NE, Emory Clinic, Building A, Atlanta, GA 30322 (E-mail: Jeffrey.Javidfar@emory.edu). JTCVS Techniques 2021;10:335-48

2666-2507

Copyright (c) 2021 The Author(s). Published by Elsevier Inc. on behalf of The American Association for Thoracic Surgery. This is an open access article under the CC BY-NC-ND license (http://creativecommons.org/licenses/by-nc-nd/4.0/).

https://doi.org/10.1016/j.xjtc.2021.08.048
}

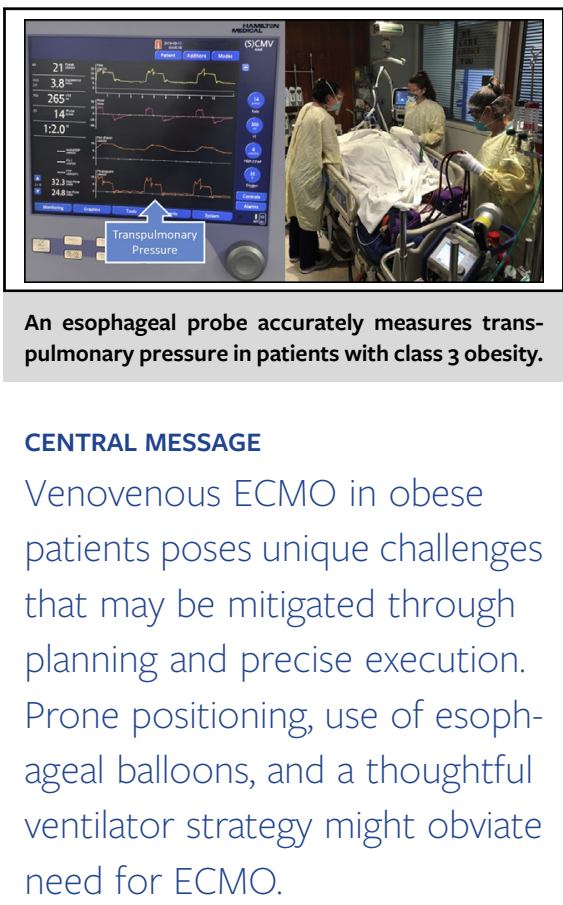

See Commentaries on pages 349 and 350 .

$V V$-ECMO for respiratory failure in obese patients and for providing an excellent guide to achieving optimal outcomes.

\section{Francis D. Pagani, MD, PhD}

Historically, obesity was not considered a major risk factor for adverse outcomes in patients with acute respiratory distress syndrome (ARDS). Commonly extracorporeal membrane oxygenation (ECMO) survivability prediction scores (ie, Respiratory Extracorporeal Membrane Oxygenation Survival Prediction score) do not consider obesity as a risk factor. ${ }^{1,2}$ Indeed, obesity typically decreased the risk of mortality. However, in patients with COVID-19, obesity (body mass index 30-40) and severe obesity (body mass index $>40$ ) are considered risk factors for poor outcomes related to acute hypoxemic respiratory failure (Table 1). ${ }^{3,4}$

Venovenous (VV) ECMO has been used increasingly in the management of ARDS secondary to severe acute respiratory failure coronavirus-2. Safe vascular cannulation and adequate blood flow generation through the ECMO circuit 
are potentially serious obstacles for health care teams caring for obese COVID-19 patients. We seek to provide an expert review of an approach to the obese patient requiring $\mathrm{VV}$ ECMO.

\section{PHYSIOLOGICAL CHALLENGES OF OBESITY}

Obesity is characterized by anatomical and physiological alterations that negatively affect pulmonary and cardiovascular function in critically ill patients. Obese patients are disproportionately susceptible to hypoxemia from chronic ventilation/perfusion mismatch. ${ }^{5}$ Increased chest wall mass and intra-abdominal pressure also contribute to a decrease in functional residual capacity. ${ }^{6}$ This might lead to an increase in pulmonary vascular resistance over time. Furthermore, patients with class 2 and 3 obesity have a higher resting oxygen consumption. ${ }^{7}$ To meet the increased oxygen demands and to perfuse the excess body mass, obese patients have increased cardiac output and blood volume. ${ }^{8}$ In normotensive obese patients, elevated cardiac output is associated with low peripheral vascular resistance and increased left ventricular enddiastolic pressure. ${ }^{9}$ Finally, patients are susceptible to obesity hypoventilation syndrome, obstructive sleep apnea, secondary pulmonary hypertension, and right ventricular failure. ${ }^{10}$

\section{SPECIAL CONSIDERATIONS FOR MECHANICAL VENTILATION BEFORE ECMO}

Mechanical ventilation in patients with class 2 and 3 obesity and ARDS should be approached in a different manner than patients with a normal habitus. ${ }^{11}$ The higher intra-abdominal pressures of obese patients can be countered with the use of reverse Trendelenburg position, which contributes to a decrease in transpulmonary pressure $\left(\mathrm{P}_{\mathrm{tp}}\right)$. It is also imperative to use the minimal fraction of inspired oxygen to achieve the required partial pressure of oxygen $\left(\mathrm{PaO}_{2}\right)$ of 55 to $80 \mathrm{~mm} \mathrm{Hg}$. Studies have shown that hyperoxemia is associated with increased mortality in critically ill patients. ${ }^{12,13}$ Especially for obese patients, hyperoxemia can exacerbate the already existing chronic inflammation associated with poor outcomes. ${ }^{14}$ Obese patients with ARDS can be optimized with low tidal volume of 4 to $6 \mathrm{cc} / \mathrm{kg}$ on the basis of predicted body weight and plateau pressure $<30 \mathrm{~cm} \mathrm{H}_{2} \mathrm{O} .{ }^{15}$ However, it is important to emphasize that lung size does not change with body weight, and tidal volumes should not be on the basis of actual body weight. Lower driving pressures have been linked to improved survival in patients with ARDS. ${ }^{16,17}$ However, this benefit did not carry over in the obese population likely because of difficulties with accurate pressure measurements. ${ }^{18}$ In patients with class 2 and 3 obesity, $P_{\text {tp }}$ can be most accurately calculated using esophageal pressure monitoring.
TABLE 1. Obesity

\begin{tabular}{lc}
\hline \multicolumn{1}{c}{ Obesity class* } & Body mass index \\
\hline Class 1 & $30-35$ \\
Class 2 & $35-40$ \\
Class 3 (Severe obesity) & $>40$ \\
\hline
\end{tabular}

*CDC definition.

\section{ESOPHAGEAL BALLOON FOR TITRATION OF POSITIVE END-EXPIRATORY PRESSURE}

The compliance of the respiratory system represents the combined compliance of the chest wall and the lungs. In patients with class 2 and 3 obesity, a sizeable fraction of applied positive end-expiratory pressure (PEEP) may be diverted to lifting the heavier chest wall and overlying subcutaneous tissue off of the lungs with little actual effect on $P_{t p}$. This might lead to mechanical ventilation-induced lung injury from repetitive opening and closing of alveoli at low lung volumes (atelectrauma). Conversely, the blind application of high levels of PEEP might result in alveolar overdistension at end inspiration (barotrauma), as well as adverse cardiovascular consequences (Table E1).

The use of an esophageal balloon can effectively titrate PEEP to increase lung compliance and improve arterial oxygenation in patients with ARDS ${ }^{19}$ (Figure 1). However, a definitive survival benefit has not yet been shown using this technique in patients with severe ARDS. ${ }^{20}$ Two assumptions are inherent. Esophageal pressure equates with pleural pressure, and pleural pressure is uniform throughout the hemithorax. ${ }^{21}$ After the esophageal balloon is correctly calibrated and positioned, $\mathrm{P}_{\mathrm{tp}}$ can easily be displayed on the ventilator monitor. This allows the bedside clinician to visually inspect the true pulmonary distending pressures at any given time. Applied PEEP is then titrated in 2-cm $\mathrm{H}_{2} \mathrm{O}$ increments to maintain a $\mathrm{P}_{\mathrm{tp}}$ PEEP of $>0 \mathrm{~cm} \mathrm{H}_{2} \mathrm{O}$ to mitigate against atelectrauma while ensuring the $\mathrm{P}_{\mathrm{tp}}$ plateau remains $<20 \mathrm{~cm} \mathrm{H}_{2} \mathrm{O}$ to avoid barotrauma (Table E2). Although the esophageal balloon has its limitations, in patients with class 2 and 3 obesity, it is reasonable to use it to optimize PEEP and $\mathrm{PaO}_{2}$ before committing to VV ECMO.

\section{PRONE POSITIONING OF OBESE PATIENTS}

Prone positioning improves oxygenation by enhancing ventilation/perfusion matching by providing a more homogenous distribution of $\mathrm{P}_{\mathrm{tp}}$ throughout the lungs. ${ }^{22}$ It either directly enhances lung compliance or indirectly improves it by reducing body wall compliance. ${ }^{23}$ In patients with severe ARDS, early proning is associated with reduced mortality. ${ }^{24}$ Prone positioning in obese patients has showed an improved $\mathrm{PaO}_{2}$ :fraction of inspired oxygen ratio without higher complication rates ${ }^{25}$ (Figure E1). 


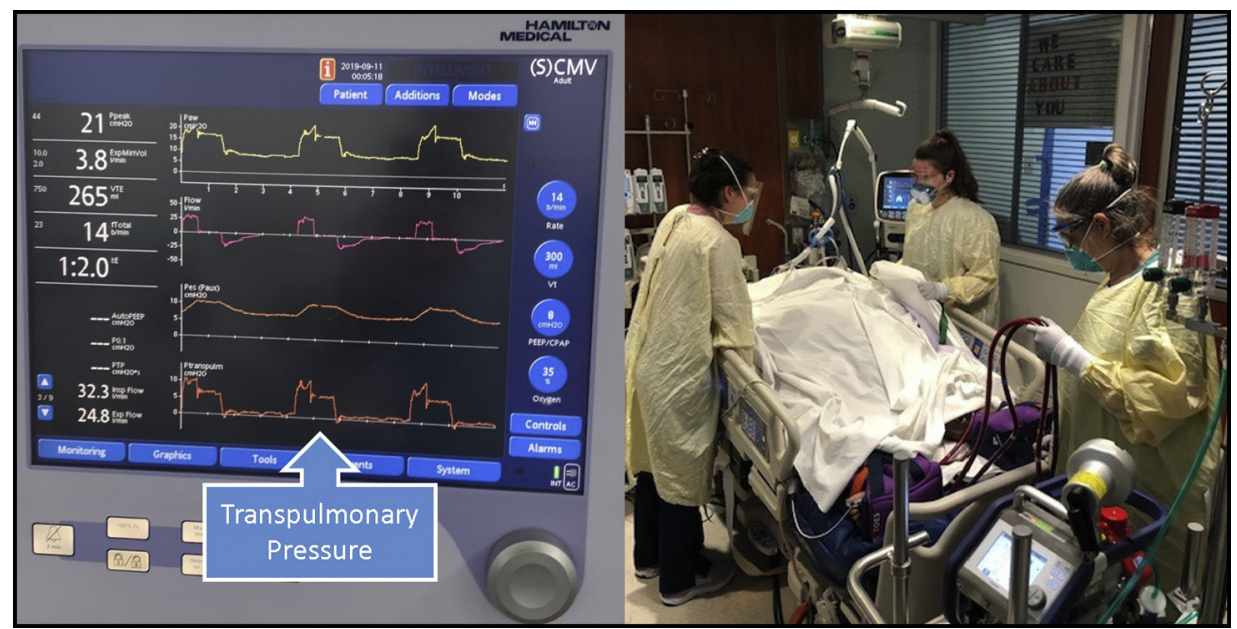

FIGURE 1. The use of an esophageal balloon can effectively titrate positive end-expiratory pressure to increase lung compliance and improve arterial oxygenation in patients with acute respiratory distress syndrome.

Before proning, it is important to develop a bedside checklist and to have well-trained staff with clear assignment and roles. Obese patients might be exposed to pressure injuries so adhesive pads should be applied to forehead, chest, iliac crests, and knees. Also, special head support devices can reduce the incidence of skin ulceration of the face. Automated proning beds have the advantage of requiring fewer staff and can facilitate rapid return to supine position (Table E3).

\section{CONSIDERATION FOR CANNULATION OF OBESE PATIENTS}

When managing the morbidly obese patient in whom conventional management is failing, ECMO support should be considered. The safe placement of the ECMO cannulas requires specific surgical expertise that can be beyond the capabilities of centers with lower ECMO case volume or experience. ${ }^{26}$ It might be prohibitive if cannulation is being contemplated remotely at a satellite hospital (Table E4).

There are general principles of cannulation for obese patients, particularly those with class 3 obesity. First, because of habitus, there is an alteration of anatomical landmarks. In these situations it is most beneficial to use 2-view, real-time ultrasound guidance to access the vessels. ${ }^{27,28}$ Because of the increased amount of soft tissue, the vessels tend to be deeper from the surface and vascular access might require longer access needles and sheaths. One might need to use steeper angles for vascular access and during percutaneous soft tissue dilation (Figure 2). The risk of guide wire kinking during cannulation is increased. One must maintain a low threshold to exchange and use fresh and/or stiffer wires when needed. The latter requires image guidance to minimize risk of vessel injury or rupture, and can be placed using exchange catheters even at the bedside. To further mitigate against kinking of the wire, the proceduralist should keep the needle angle as shallow as possible when initially accessing the vessel. Using longer, more gently tapered silicone dilators might also be useful. To assist with safe cannula placement, a second point of image guidance in the form of radiograph and/or cardiac echo (transthoracic or transesophageal) should be used.

Last, using 2 cannulas has the theoretical advantage of offering increased ECMO flows while minimizing hemolysis. In the interest of maximizing flows, use as large of a drainage cannula as possible to avoid high venous pressures $^{29}$ (Table 2). This not only facilitates enough gas exchange initially to support an obese patient, but provides a buffer of excess flow that allows for diuresis later in the patient's ECMO management course (Figure E1). Use of the largest available drainage cannula should be considered during initial cannulation. If additional flows are needed, a third cannula can be placed either in the remaining femoral vein or an upper body vein to allow for a "VVV"

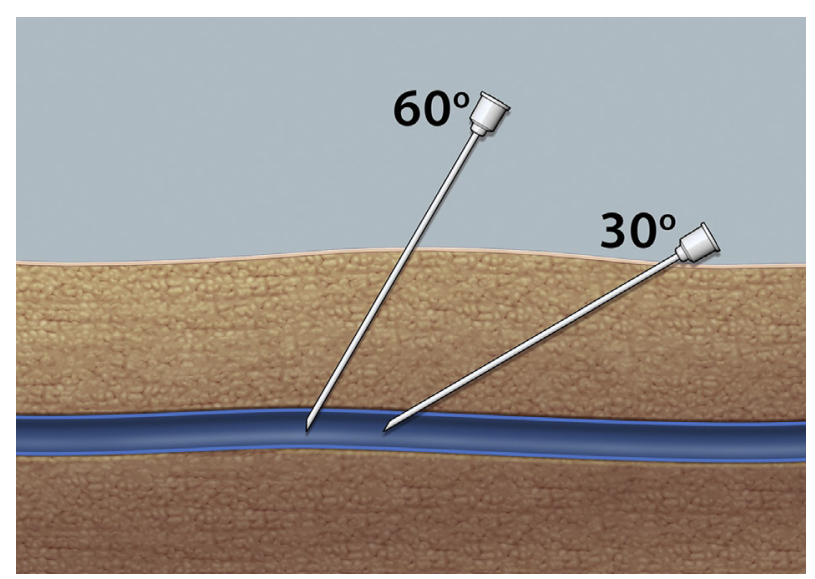

FIGURE 2. Because of depth of subcutaneous tissue, shallow needle angle might not reach the vessel. 
configuration with bicaval drainage (Figure 3, A). Alternatively, the lungs can be bypassed with a venoarterialvenous (VAV) ECMO configuration.

There are specific pros and cons to the various configurations of VV ECMO in the class 2 and 3 obese patient (Table 3). If partial cardiac support is required then VAV ECMO offers the added benefit of partial cardiac support (Table 4). Even with the use of ultrasound, accessing the cervical vessels might be challenging. The right internal jugular (IJ) vein tends to be the easiest site for peripheral cannulation in this population because it is anatomically in line with the superior vena cava. This can be for either a singlesite dual lumen cannula or as part of a femoral-IJ configuration. A dual lumen cannula has the benefit of requiring only a single vascular puncture, but should only be placed by experienced cannulators using the requisite image guidance to prevent vascular or cardiac injury. This necessitates the availability of image guidance in the intensive care unit or that the patient is stable enough for transportation to the operating room or catheterization lab. Maximum flows tend to be approximately 4.5 liters per minute (LPM), and this might be insufficient to support the class 2 and 3 obese patient in the acute phase of their ARDS. ${ }^{30}$ However, a duallumen cannula has the advantages of obviating the need for a femoral cannula, which can facilitate patient mobilization, easier rehabilitation, and increase patient comfort. ${ }^{31}$

Femoral cannulation, femoral-femoral, or femoral-IJ configuration can be used. Two cannulation sites have the advantage of greater flows due to enhanced drainage versus a single-site, dual-lumen cannula. However, a large pannus and significant amount of subcutaneous tissue can make femoral cannulation challenging. To mitigate against challenges such as kinking of guide wires and difficulties with serial dilation one should take care to meticulously retract the pannus in a secure fashion before prepping and draping.
The preferential use of the right groin might be advisable because the right femoral vein is anatomically more in line with the inferior vena cava. However, bifemoral cannulation can be performed safely at the bedside, and, if used with image guidance, offers a low risk of recirculation (Figure 3, B).

If the patient does not require high flows, IJ vein or left subclavian vein cannulation with a dual-lumen cannula might offer the advantage of obviating the need for a femoral cannula, facilitating mobilization and freeing up a peripheral venous access site (Figure 3,C). The left subclavian vein has the added advantage of being further away from the tracheostomy site and less likely to be soiled by its secretions. Because of the anatomy and habitus, radiographic guidance should be routinely used for all duallumen cannulations.

\section{CONSIDERATIONS DURING ECMO MANAGEMENT}

The primary goal of VV ECMO is to provide adequate gas exchange and oxygenation while allowing the lungs time to recover. Oxygenation depends on rate of flow, hemoglobin concentration, oxygenator surface area, and the fraction of inspired oxygen of the gas flow. To maximize oxygen delivery, high ECMO flow (6-7 LPM) is needed, which is dependent on cannula size, position, and patient volume status. Elevating serum hemoglobin levels can increase blood oxygen content. ${ }^{32}$ Finally, increasing oxygenator surface area by using 2 oxygenators in parallel can improve oxygenation and gas exchange. ${ }^{33}$ The pharmacokinetics in obese patients receiving ECMO has not been wellstudied. However, the literature shows that differences in opioid and benzodiazepine requirements were not as great as initially predicted for obese versus nonobese patients receiving VV ECMO. ${ }^{34}$

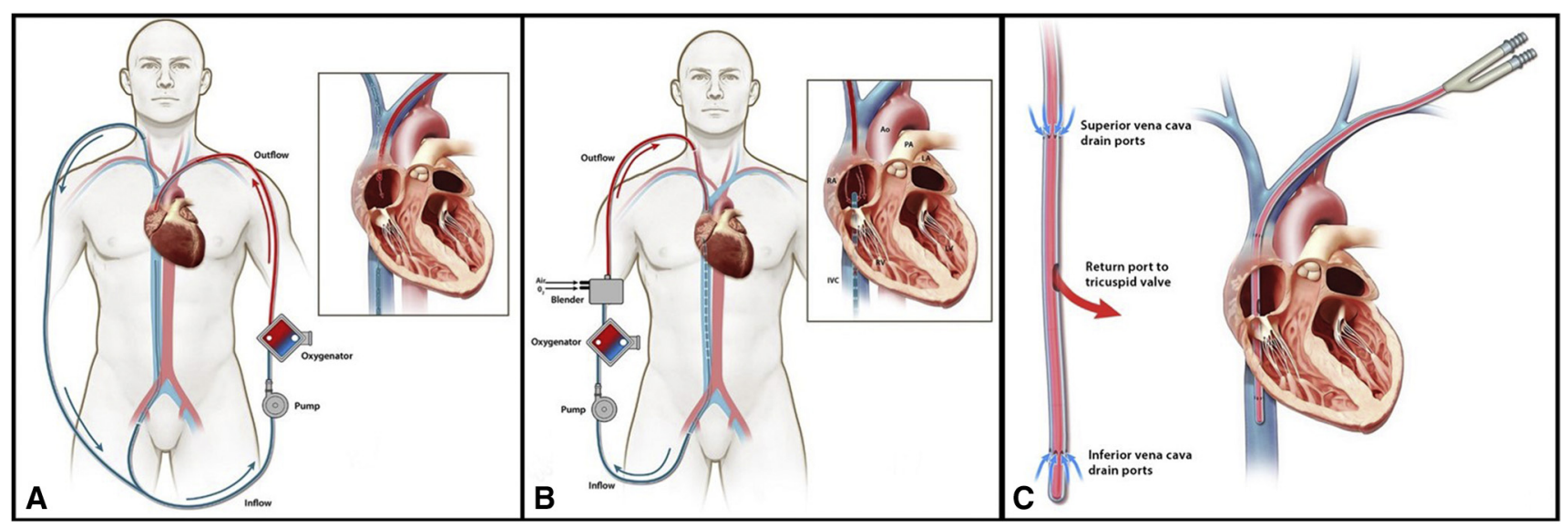

FIGURE 3. A, Extracorporeal membrane oxygenation (ECMO) flows can be maximized in a veno-venovenous ECMO configuration using the right internal jugular and right femoral veins for bicaval drainage, and the left subclavian vein for oxygenated return. B, With venovenous or veno-venovenous ECMO there is a risk of recirculation if the cannula placement is not image-guided. $\mathrm{C}$, The left subclavian vein can be used for dual lumen cannula placement. Ao, Aorta; $P A$, pulmonary artery; $L A$, left atrium; $R A$, right atrium; $R V$, right ventricle; $L V$, left ventricle; $I V C$, inferior vena cava. 
TABLE 2. Sample cannulation strategy

\begin{tabular}{|c|c|c|c|c|}
\hline \multirow[b]{2}{*}{ Cannula size } & \multicolumn{2}{|c|}{ Body mass index $<40$} & \multicolumn{2}{|c|}{ Body mass index $>40$} \\
\hline & 20 -Fr return $25-$ Fr drainage & 4-5 LPM & VV & 5.5-6 LPM \\
\hline & & & 21-Fr return & \\
\hline & & & $27-F r$ or $29-$ Fr drainage & \\
\hline & & & VVV & $>6$ LPM \\
\hline & & & 23-Fr return & \\
\hline & & & 20-Fr or $29-\mathrm{Fr}$ drainage & \\
\hline
\end{tabular}

$F r$, French; $L P M$, liters per minute; $V V$, venovenous extracorporeal membrane oxygenation; $V V V$, veno-venovenous.

\section{BEDSIDE MANAGEMENT CONSIDERATIONS}

Obese patients can be difficult to manage in the critical care setting. Prone positioning of obese patients receiving VV ECMO has specific pitfalls. Most concerning, are accidental decannulation, extubation, or removal of invasive lines from the patient. However, in experienced centers many of these complications tend to be avoided. ${ }^{35}$ Proning patients receiving ECMO is also labor-intensive and can lead to staff injuries. Furthermore, proning obese patients receiving VV ECMO can increase intra-abdominal pressures and impair ECMO flows. Finally, as discussed previously, class 2 and 3 obese patients are at an increased risk of cannula kinking, skin breakdown, and pressure ulcer formation.

\section{AIRWAY MANAGEMENT DURING ECMO}

Tracheostomy in the ECMO population is considered safe. ${ }^{36}$ After patients are receiving ECMO, each center should continue to follow its established protocols and guidelines for airway management including timing and surgical approach to tracheostomy. When possible, early tracheostomy should be considered. The use of extra-long tracheostomy tubes should be considered to minimize the risk of dislodgement, fistula formation, and tracheal injury. ${ }^{37}$

\section{PHYSICAL THERAPY DURING ECMO}

Patients with class 2 and 3 obesity who require VV ECMO are at particular risk for critical illness myopathy and muscle loss. Mobilization also poses a challenge. Practical risks include kinking of lower body cannulas due to the pannus as a result of the angle that the femoral cannula travels through the soft tissue. ${ }^{38,39}$ In instances in which 2 or more sites of cannulation are required, physical activity might be limited to bed exercises, such as active and passive range of motions activities. It is important to firmly secure the cannula and tubing to the skin with suture and attachment devices. Usually bed-based pedal bikes can be logistically prohibitive because of the habitus and ergonomics. Patients may sit up in a bed converted to the chair position. Tilt table beds specially designed for physical therapy allow for standing and weight-bearing. They can be used to build core strength without flexion at the hips.
It is easier to mobilize patients who can solely be supported using upper body dual-lumen cannula. ${ }^{40,41}$ As ECMO flow requirements decrease below 4 to 4.5 LPM, a patient can be converted to a dual-lumen cannula, and out of bed exercises can begin. This can include dangling, sit to stand, and then walking on portable treadmills. Patients can also strengthen their core by spending hours a day sitting in a chair. At the peak of their physical therapy training patients can walk laps in the intensive care unit (because they are usually off of isolation precautions by this point). Stationary bikes may also be used.

\section{ANTICOAGULATION DURING ECMO}

Patients with class 2 or 3 obesity tend to be hypercoagulable in part due to the higher inflammatory state. This, when possible, calls fora higher degree of anticoagulation. There is also a trend toward bivalirudin usage in lieu of heparin for daily anticoagulation management in VV ECMO patients. Intravenous bivalirudin has been associated with decreased number of ECMO circuit-related thrombotic events and decreased blood transfusions compared with unfractionated heparin drip. ${ }^{42}$ In practice, this can still include a heparin bolus of 5000 to 8000 units for cannulation. The initial use of heparin is on the basis of practicality and availability in patients with emergency or remote cannulations. However, it is dosed at a higher level than for nonobese patients. For maintenance, patients can be transitioned to a bivalirudin drip with activated partial thromboplastin time (aPTT) monitoring. The dosing is managed with a nomogram with a starting aPTT goal of 60 to 80 seconds. Alternatively, a heparin drip with a Factor Xa or an aPTT monitoring nomogram can be used. The anticoagulation should be titrated depending on instance and severity of events such as intracranial bleeding, gastrointestinal bleeding, and bleeding from the naso/oro pharynx or tracheostomy site. Additional benefits of bivalirudin include a short half-life, easy monitoring, and avoidance of heparininduced thrombocytopenia and/or antithrombin III deficiency. All post-ECMO patients with class 2 or 3 obesity would benefit from 4-limb surveillance ultrasound examination, because some might need continued post ECMO anticoagulation. 
TABLE 3. Pros and cons of cannula configuration

\begin{tabular}{|c|c|c|}
\hline Cannulation strategy & Pros & Cons \\
\hline \multicolumn{3}{|l|}{ Standard configurations } \\
\hline \multicolumn{3}{|l|}{ Venovenous (2 sites) } \\
\hline Femoral-femoral veins & $\begin{array}{l}\text { - Ergonomically convenient } \\
\text { during emergent bedside cannulation }\end{array}$ & $\begin{array}{l}\text { Femoral vein risks* } \\
\text { - Femoral vessels difficult to access because of depth from the skin } \\
\text { - Wires can kink and be difficult to dilate because of the habitus } \\
\text { - Pannus needs to be retracted } \\
\text { - Imaging required to prevent recirculation } \\
\text { - Exposing both groin sites difficult with large pannus } \\
\text { - IVC crowded by cannulas }\end{array}$ \\
\hline Femoral-internal jugular veins & $\begin{array}{l}\text { - RIJ in line with SVC } \\
\text { - Easier to retract pannus away } \\
\text { from } 1 \text { groin site }\end{array}$ & $\begin{array}{l}\text { LIJ risks } \dagger \\
\text { - LIJ requires imaging because of risk of innominate } \\
\text { vein injury during dilation or cannulation } \\
\text { - Femoral vein risks* } \\
\text { - Risk of recirculation } \\
\text { - Closer to tracheostomy site }\end{array}$ \\
\hline Femoral-left subclavian vein & $\begin{array}{l}\text { - Cannula does not move with neck ROM } \\
\text { - Site further from tracheostomy }\end{array}$ & $\begin{array}{l}\text { Left subclavian vein risks } \ddagger \\
\text { - Left subclavian requires imaging to prevent venous or } \\
\text { cardiac injury during dilation or cannulation } \\
\text { - Femoral vein risks* } \\
\text { - Risk of recirculation }\end{array}$ \\
\hline Venovenous (dual lumen) & $\begin{array}{l}\text { - Single site } \\
\text { - Frees up peripheral site }\end{array}$ & $\begin{array}{l}\text { - Real-time imaging to position } \\
\text { - Limited ECMO flows }\end{array}$ \\
\hline Internal jugular vein & - RIJ easy to place & $\begin{array}{l}\text { - LIJ risks } \dagger \\
\text { - Real-time imaging to prevent cardiac injury by cannula } \\
\text { - Neck cannula moves with ROM }\end{array}$ \\
\hline Left subclavian vein & $\begin{array}{l}\text { - Flows not affected by neck ROM } \\
\text { - Site further from tracheostomy }\end{array}$ & $\begin{array}{l}\text { - Left subclavian risks } \ddagger \\
\text { - Requires experienced cannulator and live imaging }\end{array}$ \\
\hline \multicolumn{3}{|l|}{ Configurations for extra flow } \\
\hline $\begin{array}{c}\text { Veno-venovenous (VVV) } \\
\text { Femoral-internal jugular } \\
\text { veins, left subclavian }\end{array}$ & $\begin{array}{l}\text { - Capacity for increased flow } \\
\text { - RIJ preferred over LIJ }\end{array}$ & $\begin{array}{l}\text { - Needs imaging to prevent recirculation } \\
\text { - Increased risk of recirculation } \\
\text { Left subclavian vein risks } \ddagger \\
\text { - Left subclavian requires imaging to prevent venous or } \\
\text { cardiac injury during dilation or cannulation } \\
\text { Femoral vein risks* } \\
\text { - Femoral vessels difficult to access because of depth from the skin } \\
\text { - Wires can kink and be difficult to dilate because of habitus } \\
\text { - Pannus needs to be retracted }\end{array}$ \\
\hline $\begin{array}{l}\text { Femoral-internal jugular } \\
\text { vein, femoral vein }\end{array}$ & - Can use RIJ or LIJ & $\begin{array}{l}\text { - Femoral vein risks* } \\
\text { LIJ risks } \dagger \\
\text { - LIJ requires imaging because of risk of innominate vein } \\
\text { injury during dilation or cannulation }\end{array}$ \\
\hline $\begin{array}{l}\text { Femoral-left subclavian } \\
\text { veins, femoral vein }\end{array}$ & $\begin{array}{l}\text { - Flows not affected by neck ROM } \\
\text { - Site further from tracheostomy }\end{array}$ & $\begin{array}{l}\text { - Left subclavian risks } \ddagger \\
\text { - Femoral vein risks* }\end{array}$ \\
\hline \multicolumn{3}{|l|}{ Venovenous (2 sites) } \\
\hline $\begin{array}{l}\text { Femoral-internal jugular } \\
\text { veins with extra-large } \\
\text { cannula }\end{array}$ & $\begin{array}{l}\text { - RIJ in line with SVC } \\
\text { - Easier to retract pannus away } \\
\text { from } 1 \text { groin site }\end{array}$ & $\begin{array}{l}\text { - Larger cannula more technically challenging to place } \\
\text { - Femoral vein risks* } \\
\text { - Risk of recirculation } \\
\text { - Potential LJ risks } \dagger\end{array}$ \\
\hline
\end{tabular}


TABLE 3. Continued

\begin{tabular}{cll}
\hline Cannulation strategy & \multicolumn{1}{c}{ Pros } & Cons \\
\hline DL-femoral vein (VV-VDL) & - Use RIJ, LIJ, or left subclavian & - Real time imaging to position \\
Upper body DL with additional & - Frees up peripheral site & - Potential LIJ risks $\dagger$ \\
femoral venous drainage line & - Can be easily converted to standard & • Potential left subclavian risks $\ddagger$ \\
& DL configuration when flow & - Femoral vein risks* \\
& requirements decrease & \\
\hline
\end{tabular}

$I V C$, Inferior vena cava; $R I J$, right internal jugular vein; $S V C$, superior vena cava; $L I J$, left internal jugular vein; ROM, range of motion; $E C M O$, extracorporeal membrane oxygenation; $D L$, dual lumen; $V V$ - $V D L$, venovenous-veno dual lumen. *Femoral vein risks. †LIJ risks. $\ddagger$ Left subclavian vein risks.

\section{MANAGEMENT OF THE RIGHT HEART DURING VV ECMO}

The pre- and peri-ECMO phases are usually when patients with refractory respiratory failure are the most hemodynamically unstable. They usually have significant acid-base disarray, and can require high doses of multiple pressors and/or ionotropes. Maximal ventilator support might fail, which includes high PEEP levels that can diminish venous return. In this situation, patients are vulnerable to varying degrees of right heart failure that can be made worse by the physiologic changes associated with class 2 and 3 obesity. If significant hemodynamic instability is being experienced, additional right heart support can be derived from inhaled pulmonary vasodilators (such as nitric oxide and epoprostenol sodium) and/or ionotropes. In our experience in obese class 2 and 3 patients with isolated respiratory failure severe right heart failure is transient. Significant hemodynamic benefits can be derived from VV ECMO alone without directed mechanical support of the right heart. VV ECMO allows for a rapid correction of $\mathrm{pH}$ and improvement in pharmacokinetics because enzymes and medications tend to work optimally at a normal $\mathrm{pH}$. As the ventilator is weaned further toward rest settings, a normalization of the previously very high PEEP improves venous return. Often after a brief period of VV ECMO, pressors, ionotropes, and the ventilator can all be weaned as the patient's hemodynamics stabilize.

However, if patients VV ECMO plus inhaled pulmonary vasodilator and ionotropes fail, then several mechanical options are available. The first would involve converting the patient from VV ECMO to VAV ECMO by adding a peripheral arterial limb. This would provide the mechanical benefit of unloading the right and left heart, but can be technically challenging in the class 2 and 3 obese patient. The arterial limb can be placed percutaneously or open in a femoral artery, but this is subject to all of the associated challenges of femoral venous cannulation including difficult access and kinking. Additionally, the patient would require a distal perfusion cannula placed into the ipsilateral superficial femoral artery. This can be particularly challenging to perform reliably at the bedside in an obese patient. In this situation, we recommend using image guidance such as ultrasound or preferably, an angiogram in a hybrid operating room or catheterization lab. Because of the depth of soft tissue required to be transversed and to prevent inadvertent dislodgement we suggest using an extra-long wire-reinforced catheter. Alternatively, a retrograde reperfusion cannula can be placed in the posterior tibial artery where the soft tissue tends to be less extensive. Other surgical options for an arterial limb include tunneled cannulation of a graft sewn onto the axillary or femoral artery. It would obviate the need for a distal perfusion cannula, but the tunneled graft and cannula can kink in the soft tissue of class 2 or 3 patients. In the axilla, there is also a potential risk of brachial plexus compression from a deep hematoma that was not detected because of the patient's habitus. Additional options include transjugular pulmonary artery cannulation. This can be via either a 2 -site technique that includes femoral venous drainage or making use of the ProTek Duo (Liva Nova), which is a dual-lumen cannula commonly placed in the right IJ vein, which bypasses the right ventricle. This cannula can be technically

TABLE 4. Pros and cons of ECMO cannula configuration; partial cardiac support

\begin{tabular}{|c|c|c|}
\hline $\begin{array}{c}\text { Cannulation strategy, } \\
\text { venovenous ( } 2 \text { sites) }\end{array}$ & Pros & Cons \\
\hline $\begin{array}{l}\text { Veno-arterial-venous (VAV) } \\
\text { - Femoral-internal jugular vein, } \\
\text { femoral artery } \\
\text { - Femoral-left subclavian vein, } \\
\text { femoral artery } \\
\text { - Femoral-femoral vein, } \\
\text { femoral artery }\end{array}$ & $\begin{array}{l}\text { - Provides partial cardiac support } \\
\text { - Heart offloaded } \\
\text { - Solution for north-south syndrome }\end{array}$ & $\begin{array}{l}\text { - Femoral vessels difficult to access because of depth from the skin } \\
\text { - Wires can kink and be difficult to dilate because of habitus } \\
\text { - Pannus needs to be retracted } \\
\text { - Technically challenging arterial cannula placement in } \\
\text { morbidly obese patients } \\
\text { - Distal perfusion cannula difficult to place and easily dislodged } \\
\text { - Might require extra-long distal perfusion cannula }\end{array}$ \\
\hline
\end{tabular}


challenging to place, commonly requires fluoroscopy, and only carries with it an indication for 6 hours of use. It would not be ideal for emergency bedside placement. Consideration for transjugular pulmonary artery cannulation should be for rare instances and performed by those with the requisite technical expertise (Figure E2).

\section{VENTILATION MANAGEMENT DURING ECMO}

Patients with class 2 or 3 obesity initially receiving VV ECMO should continue to be ventilated with similar strategies outlined herein for the pre-ECMO phase. Reverse Trendelenburg bed positioning and use of an esophageal probe can optimize respiratory mechanics while accurately recreating rest settings per ARDS Net protocols. As lung recovery occurs, the sequence for weaning of the mechanical ventilator and ECMO should conform to the ECMO center's best practices. Specifically, if a center routinely manages VV ECMO patients without positive pressure ventilation, then the strategy can be applied to select patients with class 2 or 3 obesity. The potential advantages of liberating VV ECMO patients from mechanical ventilation include earlier mobilization, decreased sedation requirements, improved mentation, and improved respiratory muscle usage. ${ }^{43}$ This would also apply to those with class 2 or 3 obesity. We would, however, caution against using these patients as the first cohort for trialing ECMO without a mechanical ventilator. Mobilizing patients with class 2 or 3 obesity while they are receiving ECMO can be rather challenging. Early tracheostomy could be a comprise by providing a protected airway while allowing for periods free from positive pressure ventilation.

\section{CONCLUSIONS}

Acute lung injury in the patients with class 2 and 3 obesity can be difficult to manage particularly as a patient progresses to ARDS. Ventilator optimization might involve the use of an esophageal probe to measure $\mathrm{P}_{\mathrm{tp}}$ 's and where feasible, proning patients should be considered before initiating VV ECMO. However, if respiratory failure is refractory to conventional means, then mechanical circulatory support is a reasonable option in appropriately resourced and experienced centers.

ECMO therapy for the class 2 and 3 obese patient population presents certain unique challenges that require thoughtful planning and meticulous execution of cannulation. Although ECMO cannulation can be a "routine" urgent procedure, it requires experienced cannulators with access to appropriate imaging. After ECMO is started, standard management practices might need to be adjusted to mitigate against mechanical and physiological challenges posed by obesity, including the need for increased flow. Mobilizing this patient population might be difficult, but it is possible and necessary to ensure a meaningful recovery.
For patients with severe morbid obesity VV ECMO should be considered an option in experienced hands.

\section{Conflict of Interest Statement}

The authors reported no conflicts of interest.

The Journal policy requires editors and reviewers to disclose conflicts of interest and to decline handling or reviewing manuscripts for which they may have a conflict of interest. The editors and reviewers of this article have no conflicts of interest.

Illustrations were graciously provided by Andy Mattlock, Department of Surgery, Emory School of Medicine. The authors thank the Washington MedStar Healthsystem ECMO team and the Emory Healthcare ECMO team for their checklists and protocols.

\section{References}

1. Schmidt M, Bailey M, Sheldrake J, Hodgson C, Aubron C, Rycus PT, et al. Predicting survival after extracorporeal membrane oxygenation for severe acute respiratory failure. The Respiratory Extracorporeal Membrane Oxygenation Survival Prediction (RESP) Score. Am J Respir Crit Care Med. 2014;189: 1374-82.

2. Ni YN, Luo J, Yu H, Wang YW, Hu YH, Liu D, et al. Can body mass index predict clinical outcomes for patients with acute lung injury/acute respiratory distress syndrome? A meta-analysis. Crit Care. 2017;21:36.

3. Centers for Disease Control and Prevention. Defining adult overweight \& obesity. Accessed February 2, 2021. https://www.cdc.gov/obesity/adult/ defining.html

4. Centers for Disease Control and Prevention. People with certain medical conditions. Accessed February 10, 2021. https://www.cdc.gov/coronavirus/2019ncov/need-extra-precautions/people-with-medical-conditions.html

5. Holley HS, Milic-Emili J, Becklake MR, Bates DV. Regional distribution of pulmonary ventilation and perfusion in obesity. J Clin Invest. 1967;46:475-81.

6. Jones RL, Nzekwu MM. The effects of body mass index on lung volumes. Chest. 2006;130:827-33.

7. Kress JP, Pohlman AS, Alverdy J, Hall JB. The impact of morbid obesity on oxygen cost of breathing (VO(2RESP)) at rest. Am J Respir Crit Care Med. 1999; 160:883-6.

8. Lemmens HJ, Bernstein DP, Brodsky JB. Estimating blood volume in obese and morbidly obese patients. Obes Surg. 2006;16:773-6.

9. Alpert MA, Omran J, Bostick BP. Effects of obesity on cardiovascular hemodynamics, cardiac morphology, and ventricular function. Curr Obes Rep. 2016;5: 424-34.

10. Kauppert CA, Dvorak I, Kollert F, Heinemann F, Jorres RA, Pfeifer M, et al. Pulmonary hypertension in obesity-hypoventilation syndrome. Respir Med. 2013; 107:2061-70.

11. De Jong A, Verzilli D, Jaber S. ARDS in obese patients: specificities and management. Crit Care. 2019;23:74.

12. Palmer E, Post B, Klapaukh R, Marra G, MacCallum NS, Brealey D, et al. The association between supraphysiologic arterial oxygen levels and mortality in critically ill patients. A multicenter observational cohort study. Am J Respir Crit Care Med. 2019;200:1373-80.

13. You J, Fan X, Bi X, Xian Y, Xie D, Fan M, et al. Association between arterial hyperoxia and mortality in critically ill patients: a systematic review and metaanalysis. J Crit Care. 2018;47:260-8.

14. González-Muniesa P, Garcia-Gerique L, Quintero P, Arriaza S, Lopez-Pascual A, Martinez JA. Effects of hyperoxia on oxygen-related inflammation with a focus on obesity. Oxid Med Cell Longev. 2015;2015:8957827.

15. Brower RG, Matthay MA, Morris A, Schoenfeld D, Thompson BT, Wheeler A. Ventilation with lower tidal volumes as compared with traditional tidal volumes for acute lung injury and the acute respiratory distress syndrome. N Engl J Med. 2000;342:1301-8

16. Guérin C, Papazian L, Reignier J, Ayzac L, Loundou A, Forel JM, et al. Effect of driving pressure on mortality in ARDS patients during lung protective mechanical ventilation in two randomized controlled trials. Crit Care. 2016;20:384. 
17. Amato MBP, Meade MO, Slutsky AS, Brochard L, Costa ELV, Schoenfeld DA, et al. Driving pressure and survival in the acute respiratory distress syndrome. $N$ Engl J Med. 2015;372:747-55.

18. De Jong A, Cossic J, Verzilli D, Monet C, Carr J, Conseil M, et al. Impact of the driving pressure on mortality in obese and non-obese ARDS patients: a retrospective study of 362 cases. Intensive Care Med. 2018;44:1106-14.

19. Talmor D, Sarge T, Malhotra A, O'Donnell CR, Ritz R, Lisbon A, et al. Mechanical ventilation guided by esophageal pressure in acute lung injury. $N$ Engl J Med. 2008;359:2095-104.

20. Beitler JR, Sarge T, Banner-Goodspeed VM, Gong MN, Cook D, Novack V, et al. Effect of titrating positive end-expiratory pressure (PEEP) with an esophageal pressure-guided strategy vs an empirical high PEEP-Fio2 strategy on death and days free from mechanical ventilation among patients with acute respiratory distress syndrome: a randomized clinical trial. JAMA. 2019;321:846-57.

21. Sahetya S, Brower RG. The promises and problems of transpulmonary pressure measurements in acute respiratory distress syndrome. Curr Opin Crit Care. 2016; 22:7-13.

22. Richard JC, Bregeon F, Costes N, Bars DLE, Tourvieille C, Lavenne F, et al. Effects of prone position and positive end-expiratory pressure on lung perfusion and ventilation. Crit Care Med. 2008;36:2373-80.

23. Mentzelopoulos SD, Zakynthinos SG, Roussos C, Tzoufi MJ, Michalopoulos AS. Prone position improves lung mechanical behavior and enhances gas exchange efficiency in mechanically ventilated chronic obstructive pulmonary disease patients. Anesth Analg. 2003;96:1756-67.

24. Guérin C, Reignier J, Richard JC, Beuret P, Gacouin A, Boulain T, et al. Prone positioning in severe acute respiratory distress syndrome. $N$ Engl J Med. 2013; 368:2159-68.

25. De Jong A, Molinari N, Sebbane M, Prades A, Futier E, Jung B, et al. Feasibility and effectiveness of prone position in morbidly obese patients with ARDS: a case-control clinical study. Chest. 2013;143:1554-61.

26. Rupprecht L, Lunz D, Philipp A, Lubnow M, Schmid C. Pitfalls in percutaneous ECMO cannulation. Heart Lung Vessel. 2015;7:320-6.

27. Ull C, Buchwald D, Strauch J, Schildhauer TA, Swol J. Extremely obese patients treated with venovenous ECMO-an intensivist's challenge. Am J Emerg Med. 2015;33:1720. e1723-4.

28. Swol J, Buchwald D, Dudda M, Strauch J, Schildhauer TA. Veno-venous extracorporeal membrane oxygenation in obese surgical patients with hypercapnic lung failure. Acta Anaesthesiol Scand. 2014;58:534-8.

29. Kon ZN, Dahi S, Evans CF, Byrnes KA, Bittle GJ, Wehman B, et al. Class III obesity is not a contraindication to venovenous extracorporeal membrane oxygenation support. Ann Thorac Surg. 2015;100:1855-60.

30. Accessed November 15, 2021. https://www.getinge.com/dam/hospital/documents/ english/avalon_elite_brochure-en-non_us.pdf
31. Rubino A, Vuylsteke A, Jenkins DP, Fowles J, Hockings L, Valchanov K. Direc complications of the Avalon bicaval dual-lumen cannula in respiratory extracorporeal membrane oxygenation (ECMO): single-center experience. Int J Artif Organs. 2014;37:741-7.

32. Bartlett RH. Physiology of gas exchange during ECMO for respiratory failure. $J$ Intensive Care Med. 2017;32:243-8.

33. Malik A, Shears LL, Zubkus D, Kaczorowski DJ. Parallel circuits for refractory hypoxemia on venovenous extracorporeal membrane oxygenation. J Thorac Cardiovasc Surg. 2017;153:e49-51.

34. Verkerk BS, Dzierba AL, Muir J, Der-Nigoghossian C, Brodie D, Bacchetta MD et al. Opioid and benzodiazepine requirements in obese adult patients receiving extracorporeal membrane oxygenation. Ann Pharmacother. 2020;54:144-50.

35. Culbreth RE, Goodfellow LT. Complications of prone positioning during extracorporeal membrane oxygenation for respiratory failure: a systematic review. Respir Care. 2016;61:249-54.

36. Salna M, Tipograf Y, Liou P, Chicotka S, Biscotti M, Agerstrand C, et al. Tracheostomy is safe during extracorporeal membrane oxygenation support. ASAIO J. 2020;66:652-6.

37. Barrera SC, Sanford EJ, Ammerman SB, Ferrell JK, Simpson CB, Dominguez LM. Postoperative complications in obese patients after tracheostomy. OTO Open. 2020;4:1-6.

38. Wells CL, Forrester J, Vogel J, Rector R, Tabatabai A, Herr D. Safety and feasibility of early physical therapy for patients on extracorporeal membrane oxygenator: University of Maryland Medical Center experience. Crit Care Med. 2018;46:53-9.

39. Ko YJ, Cho YH, Park YH, Lee H, Suh GY, Yang JH, et al. Feasibility and safety of early physical therapy and active mobilization for patients on extracorporeal membrane oxygenation. ASAIO J. 2015;61:564-8.

40. Javidfar J. The challenges faced with early mobilization of patients on extracorporeal membrane oxygenation. Crit Care Med. 2018;46:161-3.

41. Abrams D, Javidfar J, Farrand E, Mongero LB, Agerstrand CL, Ryan P, et al Early mobilization of patients receiving extracorporeal membrane oxygenation: a retrospective cohort study. Crit Care. 2014;18:R38.

42. Rivosecchi RM, Arakelians AR, Ryan J, Murray H, Raj Ramanan, Gomez H, et al. Comparison of anticoagulation strategies in patients requiring venovenous extracorporeal membrane oxygenation: heparin versus bivalirudin. Crit Care Med. 2021;49:1129-36.

43. Levin NM, Ciullo AL, Overton S, Mitchell N, Skidmore CR, Tonna JE. Characteristics of patients managed without positive pressure ventilation while on extracorporeal membrane oxygenation for acute respiratory distress syndrome. J Clin Med. 2021;10:251.

Key Words: ECMO, venovenous ECMO, morbid obesity 
Management of Refractory Hypoxia in Class 2 and 3 Obese Patients with ARDS
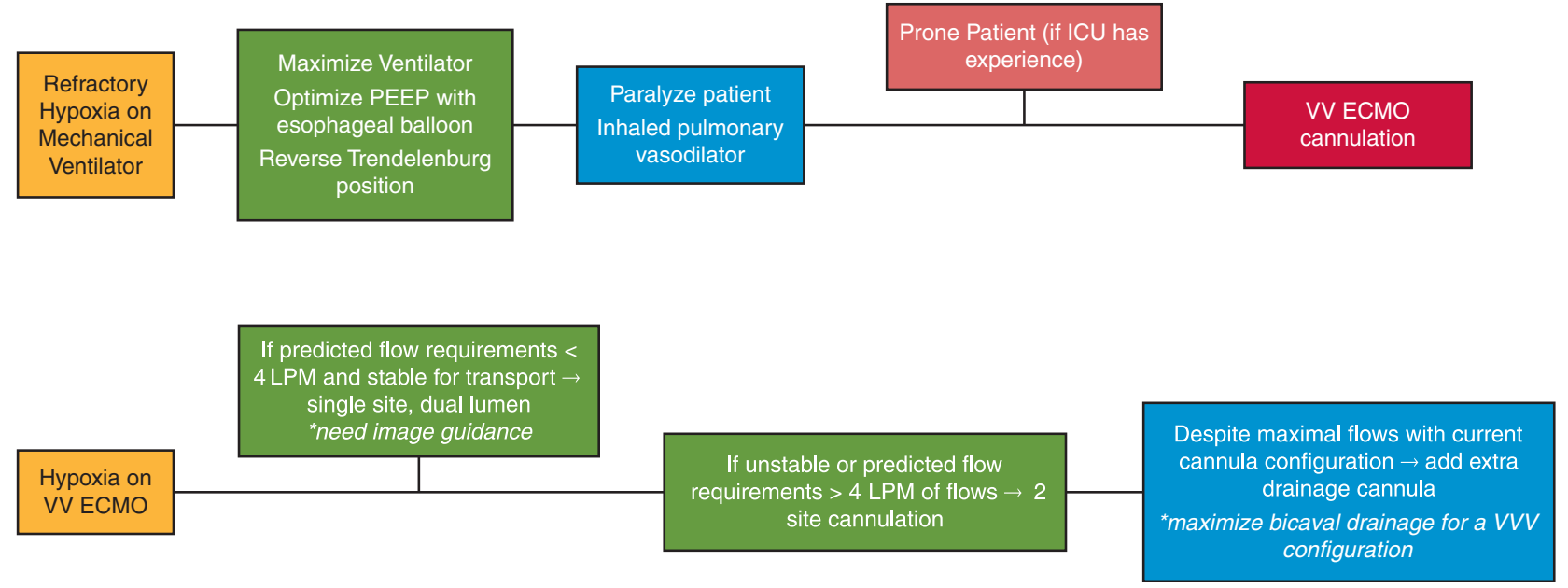

FIGURE E1. An algorithm for the management of hypoxia in obese patients with acute respiratory distress syndrome (ARDS) that is refractory to the mechanical ventilator and standard venovenous $(V V)$ extracorporeal membrane oxygenation $(E C M O)$ cannulation. PEEP, Positive end-expiratory pressure; $I C U$, intensive care unit; $L P M$, liters per minute; $V V V$, veno-venovenous.

Management of Right Heart Failure in Class 2 and 3 Obese Patients with ARDS

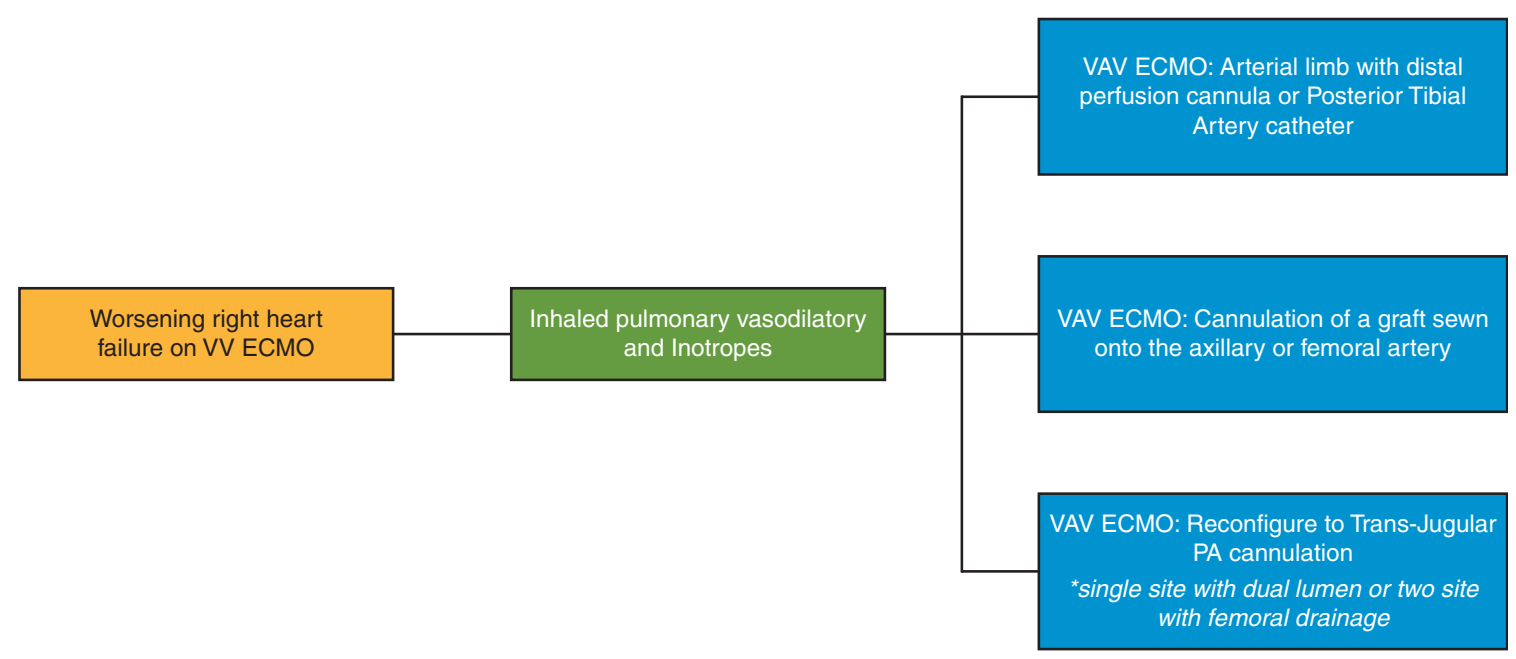

FIGURE E2. An algorithm for the management of worsening right heart in obese patients with acute respiratory distress syndrome (ARDS) who are already receiving venovenous $(V V)$ extracorporeal membrane oxygenation $(E C M O)$. VAV, Venoarterial-venous; $P A$, pulmonary artery. 
TABLE E1. Key points

- In obese patients a sizeable fraction of applied PEEP might affect volume of the chest wall with little effect on transpulmonary pressure.

- In obese patients, the "blind" application of high levels of PEEP can lead to barotrauma

- In morbidly obese patients, consider the use of an esophageal balloon to optimize PEEP and arterial $\mathrm{PaO}_{2}$ before committing to venovenous ECMO PEEP, Positive end-expiratory pressure; $\mathrm{PaO}_{2}$, partial pressure of oxygen; $E C M O$, extracorporeal membrane oxygenation.

\section{TABLE E2. Definitions}

Transpulmonary pressure: the distending pressure of lung tissue expressed mathematically as:

transpulmonary pressure $=$ alveolar pressure - pleural pressure

Transpulmonary plateau pressure: transpulmonary pressure measured at end inhalation $=$ plateau pressure - esophageal pressure at end inhalation

Transpulmonary PEEP: transpulmonary pressure measured at end exhalation $=$ PEEP - esophageal pressure at end exhalation

PEEP, Positive end-expiratory pressure. 
TABLE E3. Ceiling lift proning checklist for ECMO patients

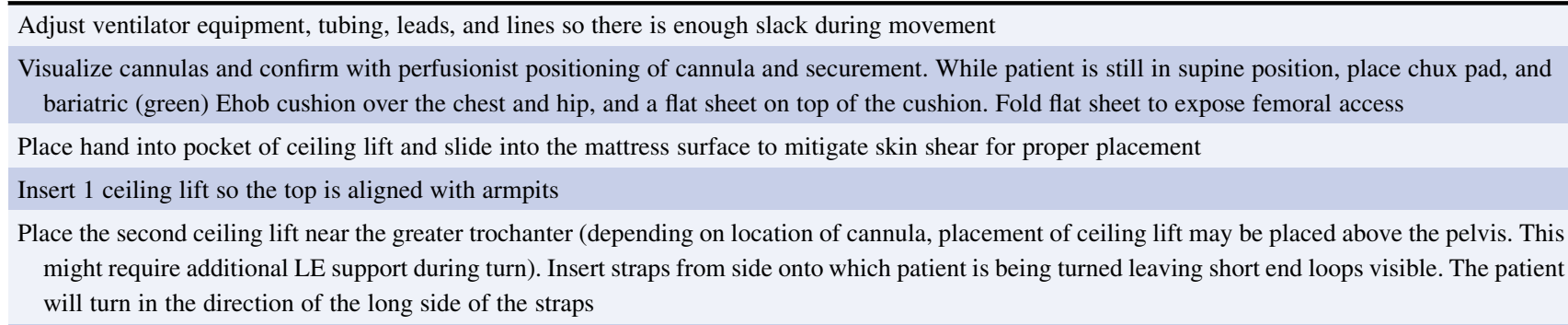

Tuck patient's hand under each hip

Wrap the edge of the sheets as closely as possible to the patient's body (like a burrito) and inflate the bed to the maximum

Lower sling bar and rotate it parallel to length of the patient. Attach the longer loop from the side onto which the patient is being turned, and the short loop from the short side of the ceiling lift, taking care to ensure the strap is seated properly on sling bar

One caregiver raises the sling bar until there is tension in the straps, then the team confirms that all the required loops are secure in the sling bar

Perfusionist is responsible for visualizing cannulas throughout the turn

Ensure the team member at the head of the bed is responsible for initiating the turn maneuver via a verbal countdown, as well as securing the patients ETT and head throughout the maneuver. At this point, the patient is ready to be lifted

On the count of 3 , the caregiver on the side from which the patient is being turned away will operate the lift, while the other caregiver(s) monitor the lines and patient's response

The caregiver at the head of bed will monitor and support the patient's head and airway. Caregivers at the foot of the bed are responsible for managing the LEs

Upon lifting, the lift equipment will begin to rotate the patient to the side. The lift movement is slow and controlled

Lift the patient high enough so they easily slide, but do not lift the patient fully off the bed. Slide patient to opposite side from which you are turning so they are centered when proned. The team should continue to manage tubing and lines as patient is being lowered

At this point, while patient suspended in lift, place flat sheet and chux pad on bed surface.

When all caregivers indicate they are ready, the person at the patients' back lowers the patient and guides them into the prone position

Position patient's head on prone pillow, Z-Flo, or air waffle cushion, in a manner that minimizes pressure of holder and tube to face and enables visualization of the ETT. The ceiling lift positioners can remain under the patient for returning the patient to supine position

Perfusionist to assess cannula and flow, reposition as needed

Position LEs on pillows to prevent pressure on bony prominences

Return ICU bed to normal mattress setting

Before exiting the room, intensivist/APP to monitor vitals and assess patient's tolerance to position

When returning the patient to the supine position, simply reconnect the ceiling lift to the bar in the same manner as when proning and follow the same procedures described above to return to supine position

Please note, when returning the patient from prone to supine, ceiling lift used in lower portion of body should be inserted with care to avoid disturbing/ dislodging femoral cannula access

Z-Flo is from Mölnlycke Health Care. $L E$, Lower extremity; $E T T$, endotracheal tube; $I C U$, intensive care unit; $A P P$, advanced practice provider. 
TABLE E4. ECMO transport supplies (sample packing list)

CardioHelp console bag

Quantity

Maquet CardioHelp with hand crank

Maquet CardioHelp console

Bottle sterile saline

Tumi syringe

Baxter Plasma Lyte-A (priming)

Sterile metal basin

Power extension cord

Transport sterile instrument pan

1

1

1

CardioHelp circuit bag

Maquet HLS pack

Transport heater/water

\begin{tabular}{|c|c|c|}
\hline Black cannula bag (long) & Location & \\
\hline Vascular dilator kit & Top - middle pocket & 2 \\
\hline Maquet Avalon access/dilator kit $210 \mathrm{~cm}$ & Large compartment - top side & 2 \\
\hline \multicolumn{2}{|l|}{ Medtronic Fem Ven cannula Carmeda2 } & 2 \\
\hline Medtronic Fem Ven 21-Fr cannula & Large compartment - top side & 2 \\
\hline Medtronic Fem Ven 25Fr cannula & Large compartment - top side & 2 \\
\hline Maquet HLS Fem Ven 29Fr cannula & Large compartment - bottom side & 2 \\
\hline Maquet HLS Fem Ven 23Fr cannula & Large compartment - bottom side & 2 \\
\hline Maquet HLS Fem Ven 25Fr cannula & Large compartment - bottom side & 2 \\
\hline Fem Flex Fem Art 16-Fr cannula & Mid compartment & 2 \\
\hline Fem Flex Fem Art 18-Fr cannula & Mid compartment & 2 \\
\hline Fem Flex Fem Art 20-Fr cannula & Mid compartment & 2 \\
\hline Medtronic EOPA 22-Fr cannula & Mid compartment & 2 \\
\hline Teleflex/Arrow 6-Fr introducer (lower leg) & Underside of mid compartment - larger pocket & 2 \\
\hline Teleflex/Arrow 8-Fr introducer (lower leg) & Underside of mid compartment - larger pocket & 2 \\
\hline Perfusion clamps & Underside of mid compartment - smaller pocket & 6 \\
\hline Connector $3 / 8-3 / 8$ & Top - left pocket & 3 \\
\hline \multicolumn{2}{|l|}{ Connector $3 / 8-3 / 8-3 / 8$} & 3 \\
\hline Extra $3 / 8$ tubing & Large compartment - top side & 1 \\
\hline 1/4-inch supplemental (yellow) tubing & Large compartment - top side & 1 \\
\hline 1/4-inch male swivel & Top-left pocket & 4 \\
\hline Boston Scientific Amplatz wire & Mid compartment & 2 \\
\hline Micropuncture kit & Underside of mid compartment - larger pocket & 6 \\
\hline Cook Medical Rosen wire & Mid compartment & 2 \\
\hline \multicolumn{3}{|l|}{ Black bag (small) } \\
\hline \multicolumn{2}{|l|}{ Kerlex gauze } & 2 \\
\hline \multicolumn{2}{|l|}{ Sterile $4 \times 4$} & 4 \\
\hline \multicolumn{2}{|l|}{ Sterile towels } & 4 \\
\hline \multicolumn{2}{|l|}{ Sterile gowns } & 4 \\
\hline \multicolumn{3}{|l|}{ Sterile gloves, multiple sizes } \\
\hline \multicolumn{2}{|l|}{ ACT Machine/PowerCord } & 1 \\
\hline \multicolumn{2}{|l|}{ ACT LR cuvettes } & 6 \\
\hline \multicolumn{2}{|l|}{ Istat $\mathrm{ABG}$ machine } & 1 \\
\hline
\end{tabular}


TABLE E4. Continued

Black bag (small)

Istat Cartridges/Istat LQC

Syringes/blunt tip needle

3/4 Sterile drape

Chlora Prep

Sterile intravenous tubing (short)

0 Silk stitch multipack

Tegaderm

Arterial line transducer Safe Set 2

Tumi syringe

Bulb syringe

Fem, Femoral; Ven, venous; $F r$, French; $A r t$, artery; $A C T$, activated clotting time; $L R$, lactated ringers; $A B G$, arterial blood gas; $L Q C$, liquid quality control. 